\title{
Dipole Moment and Charge Reorganization in Photoredox Catalysts
}

\author{
J.D. Earley ${ }^{1,2+}$, A. Zieleniewska ${ }^{1+}$, H.H. Ripberger ${ }^{3}$, M.S. Lazorski ${ }^{1,4}$, Z.J. Mast ${ }^{1}$, H. Sayre ${ }^{3}$, \\ R.R. Knowles ${ }^{3}$, J.K. McCusker ${ }^{5}$, G.D. Scholes ${ }^{3}$, O.G. Reid ${ }^{1,6}$, and G. Rumbles ${ }^{1,2,6^{*}}$
}

${ }^{1}$ National Renewable Energy Lab, Golden, 80401, USA

${ }^{2}$ University of Colorado Boulder, Department of Chemistry, Boulder, 80309, USA

${ }^{3}$ Princeton University, Department of Chemistry, Princeton, 08544, USA

${ }^{4}$ Metropolitan State University of Denver, Department of Chemistry and Biochemistry, Denver, 80204, USA

${ }^{5}$ Michigan State University, Department of Chemistry, Ann Arbor, 48824, USA

${ }^{6}$ University of Colorado Boulder, Renewable and Sustainable Energy Institute, Boulder, 80309, USA

*Garry.Rumbles@nrel.gov

+these authors contributed equally to this work

\begin{abstract}
We report evidence of excited-state ion pair reorganisation in a cationic iridium (III) photoredox catalyst in 1,4-dioxane. Microwave-frequency dielectric-loss measurements combined with accurate calculations of dipolar relaxation time allow us to assign both ground and excited-state molecular dipole moments in solution and determine the polarizability volume in the excitedstate. These measurements show significant changes in ground-state dipole moment between $\left[\operatorname{Ir}\left[d F\left(C F_{3}\right) p p y\right]_{2}(d t b p y)\right] P F_{6}$ (10.74 Debye) and $\left[\operatorname{Ir}\left[d F\left(C F_{3}\right) p p y\right]_{2}(d t b p y)\right] B A r_{4}^{F}$ (4.86 Debye). Photoexcitation of each complex results in population of highly mixed ligand centered and metal-to-ligand charge transfer states with enormous polarizability. Relaxation to the lowest lying excited-state leads to a negative change in the dipole moment for $\left[\operatorname{Ir}\left[d F\left(\mathrm{CF}_{3}\right) p p y\right]_{2}(d t b p y)\right] P F_{6}$, and a positive change in dipole moment for $\left[\operatorname{Ir}\left[d F\left(C_{3}\right) \text { ppy }\right]_{2}(d t b p y)\right] B A r_{4}^{F}$. These observations are consistent with a sub-nanosecond reorganization with the $P_{6}^{-}$counter-ion, which cancels the dipole moment of the lowest lying excited-state, a process which is absent for the $B A r_{4}^{F-}$ counter-ion. Taken together, these observations suggest contact-ion pair formation between the cationic metal complex and the $\mathrm{PF}_{6}^{-}$anion and, at most, solvent-separated pairing with $\mathrm{BAr}_{4}{ }^{--}$. The dynamic ion pair reorganisation we observe with the $P F_{6}^{-}$ counter-ion may substantially modify both the thermodynamic potential available for electron transfer and kinetically inhibit oxidative catalysis, as the anion moves to cover the positively charged end of the molecule, providing a possible mechanistic explanation for recently observed trends in the catalytic activity of these complexes as a function of anion identity in low-polarity solvents. These tunable ion-pair dynamics could prove to be a valuable tool for tailoring the reactivity of both new and extant photocatalysts.
\end{abstract}

\section{Introduction}

Photoredox catalysts are able to drive reactions with high kinetic or thermodynamic barriers by harnessing the energy of light. This in-situ preparation of highly oxidizing or reducing reagents from stable precursors allows gentler more selective reaction conditions, opening the doors to many new reactions such as the processing of lignin into stock chemical species to aryl-dehalogenation reactions. ${ }^{1-8}$

Cyclometalated $\left(\mathrm{C}^{\wedge} \mathrm{N}\right)$ and polypyridyl $\left(\mathrm{N}^{\wedge} \mathrm{N}\right)$ complexes of $d_{6}$ metals are some of the most promising transition metal photoredox catalysts to date. Heteroleptic compounds incorporating $\left(\mathrm{C}^{\wedge} \mathrm{N}\right)$ and $\left(\mathrm{N}^{\wedge} \mathrm{N}\right)$ ligands, as in $\left[\operatorname{Ir}(\text { ppy })_{2}(\text { bpy) }]^{+}\right.$complexes, benefit from independent tunability of HOMO and LUMO levels via ligand architecture. ${ }^{9-20}$ Yet, the relationship between structural/environmental perturbations and changes in the intricate excited-state manifold of $\left[\operatorname{Ir}(\text { ppy })_{2}(\text { bpy })\right]^{+}$complexes are hard to capture with existing spectroscopies, making it commensurately difficult to understand all the factors that modulate their photoredox activity. Tuning of the redox potentials, absorption energy, excited-state lifetime, and quantum yield, are well known criteria, but other factors can play an important role. ${ }^{21-24}$ For instance, recent work suggests that the size and polarity of the counter-ion effects the efficiency of the catalytic cycle, ${ }^{25-31}$. While many reports note spectral changes due to ion-pairing in common photoredox catalysts, ${ }^{30,32-36}$ there are currently no direct quantitative methods that can probe the ground and excited-state electron density distribution to understand how ion pairing influences the excited state structure and evolution. Here, we introduce a modern implementation of time-resolved dielectric-loss spectroscopy (TRDL) to investigate how counter-ion identity influences the excited-state charge distribution within an important photoredox catalyst, $\left[\operatorname{Ir}\left[d F\left(\mathrm{CF}_{3}\right) \text { ppy }\right]_{2}(d t b p y)\right] X .^{37-39}$ We find large differences in both the ground and excited-state dipole moments depending on 
whether $X$ is a small associating anion $\left(\mathrm{PF}_{6}^{-}\right)$that forms a contact-ion pair vs. a large one that either dissociates or forms a solvent-separated pair $\left(B A r_{4}^{F-}\right)$. These results suggest that ion pairing and the control it confers over both ground-state and excited-state structure could be a heretofore underappreciated factor that modulates reactivity in ionic photoredox catalysts.

In what follows, we describe our modern implementation of TRDL using quantitative methods to measure complex permittivity, and calculations of the dipole moment of both ground and excited-state molecules in solution. We use electromagnetic simulations to relate measured microwave resonator properties to the complex permittivity of the sample. Combined with new quantitative calculations of the dipolar relaxation time, we are able to extract the molecular dipole moment from dielectric-loss data. We verify the validity of our methods by studying the ground and excited-state dipole moments of N,N-dimethylaminobenzonitrile (DMABN) in 1,4-dioxane; a model compound with a well understood intramolecular charge transfer excited-state. Finally, we apply this approach to understand the excited-state charge reorganization in $\left[\operatorname{Ir}\left[d F\left(C F_{3}\right) p p y\right]_{2}(d t b p y)\right] P F_{6}$ and $\left[\operatorname{Ir}\left[d F\left(C F_{3}\right) p p y\right]_{2}(d t b p y)\right] B A r_{4}^{F}$.

\section{Dielectric-loss Spectroscopy Background}

Flash-photolysis time-resolved dielectric-loss (fp-TRDL) spectroscopy is a perturbative technique developed to measure the time dependent evolution of a molecule's electron density distribution; it is one of only a few methods to measure a solution-phase molecule's excited-state dipole moment in situ without relying on emission, which can bias observations to bright states and limit the broad applicability of the technique, for instance with dark molecular triplet states. ${ }^{40-43}$ In this technique, microwave radiation is used to measure the complex permittivity $\left(\varepsilon_{r}=\varepsilon^{\prime}-i \varepsilon^{\prime \prime}\right)$ of a sample by monitoring the phase and amplitude changes of a transmitted waveform. Performing this measurement inside a resonance cavity increases the effective path length through the sample and thus improves the sensitivity to small changes in $\varepsilon_{r}$. At the X-band frequencies used in these experiments $(8.2-12.4 \mathrm{GHz})$, changes in $\varepsilon_{r}$ from a solution are a function of solute concentration, a solute's dipole moment $(\mu)$, and its polarizability volume $\left(V_{p}\right)$. Selectively exciting a photoredox catalyst with a pulsed laser allows measurement of $\Delta \varepsilon_{r}$ due to the solute molecule's change in dipole moment and polarizability volume - the change in charge density and localization from the ground-state to the excited-state. Ultimately, measuring both $\varepsilon_{r}$ and $\Delta \varepsilon_{r}$ captures the dipole moment and polarizability volume of a solution-phase sample, both in the ground and excited-states.

Our implementation of dielectric-loss spectroscopy consists of placing a sample inside a resonant microwave cavity and measuring the change in cavity characteristics caused either as a function of ground or excited-state solute concentration. Electromagnetic modeling is then used to relate the complex permittivity of the sample to the resonator properties, allowing quantitative permittivity measurements. The modeling is combined with quantitative simulation of the dipolar relaxation time to extract the molecular dipole moment and polarizability volume of the solute. [SI section COMSOL Simulation of Microwave Cavities]

For this study, a new microwave resonance cavity (figure 1) was designed and fabricated to measure solution-phase samples based on a design by Fessenden et. al.. ${ }^{44}$ The experimental set-up consists of a $5 \mathrm{~mm}$ diameter EPR tube placed in the cavity at one electric field maximum of the $T E_{102}$ standing wave, and a single slit in the end wall allowing for photoexcitation. A circular iris structure is placed between the feeding waveguide and the cavity in order to couple microwave radiation into the cavity, and define one end of the resonator. For all samples in this work, a $9.20 \mathrm{~mm}$ diameter iris was used unless otherwise stated. Maxwell's equations were solved using the computer aided drafting (CAD) model and radio-frequency (RF) simulation package COMSOL Multiphysics (v4.3a). This allowed us to optimize the sample position and iris diameter before fabricating the microwave cavity; this design process has been described in our previous work. ${ }^{45}$ 


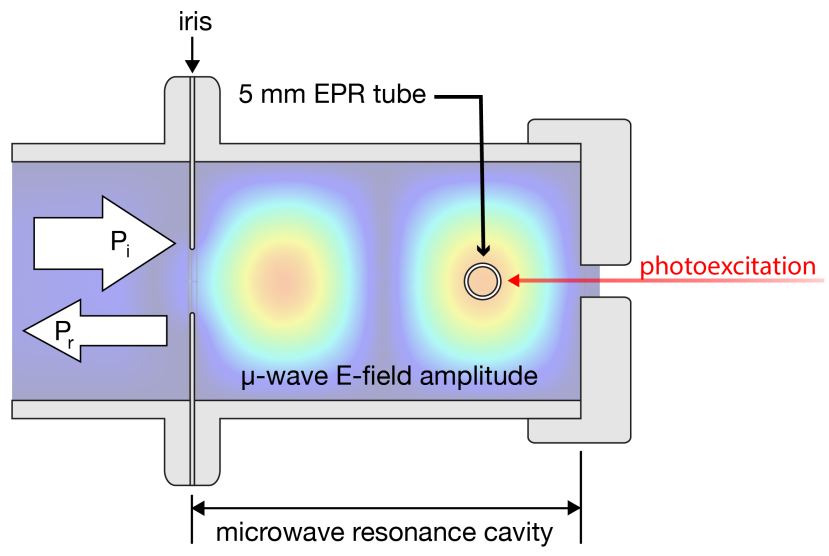

Figure 1. COMSOL Multiphysics electric-field amplitude solution for our solution-phase microwave resonance cavity.

After manufacturing the cavity, the reverse process was used to model the manufactured cavity in COMSOL to account for manufacturing defects, and extract quantitative values for the sensitivity of the cavity characteristics to the complex permittivity of the sample $\left(\varepsilon^{\prime}\right.$ and $\left.\varepsilon^{\prime \prime}\right)$. [described in section COMSOL Simulation of Microwave Cavities of the SI] By iteratively stepping the simulated sample's $\varepsilon^{\prime}$ and $\varepsilon^{\prime \prime}$ inside the EPR tube, we create a look-up table of simulation results that we then use as a numerical fit function to quantify the dielectric properties of solution-phase samples; this enables us to convert measured microwave power reflectance as a function of frequency about the cavity resonance to $\varepsilon^{\prime}$ and $\varepsilon^{\prime \prime}$.

The complex permittivity of a solution-phase sample is a function of both the dipole moment and polarizability of all the molecules therein, and for dilute solutions, it may be expressed as the sum of contributions from the solvent and the solute. This relationship is simplified if the complex permittivity can be separated into its real and imaginary components (described by equation (1)) as the imaginary permittivity is only a function of the dipole moment.

$$
\varepsilon_{r}=\left[\varepsilon^{\prime}-i \varepsilon^{\prime \prime}\right]_{\text {solute }}+\left[\varepsilon^{\prime}-i \varepsilon^{\prime \prime}\right]_{\text {solvent }}
$$

The remainder of this discussion will focus only on the solute's contribution to the permittivity as the solvent's contribution is subtracted out in the experimental procedure.

Firstly, the real part of the solute's permittivity can be separated into two components which describe the dipole contribution $\left(\varepsilon_{D}^{\prime}\right)$ and the electronic polarizability contribution $\left(\varepsilon_{E}^{\prime}\right)$.

$$
\varepsilon^{\prime}=\varepsilon_{D}^{\prime}+\varepsilon_{E}^{\prime}
$$

Both components are derived from Debye's polarity equations of a polar molecule rotating in an electric field. ${ }^{46}$ The dipole contribution to the real permittivity is described as:

$$
\varepsilon_{D}^{\prime}=\frac{(\varepsilon(0)+2)(\varepsilon(\infty)+2)}{27 \varepsilon_{0} k_{B} T} \frac{\mu^{2}}{(\omega \theta)^{2}} N f(\omega \theta)
$$

Where $N$ is the solute concentration in molecules $/ \mathrm{m}^{3}, \varepsilon_{0}$ is the permittivity of free space, $\varepsilon(0)$ is the DC dielectric constant of the solvent, $\varepsilon(\infty)$ is the high-frequency dielectric constant of the solvent (which can be approximated as the square-root of the refractive index, $\sqrt{n}), \omega$ is the microwave angular frequency, $\mu$ is the molecule's dipole moment, $k_{B}$ is the Boltzmann constant, $\theta$ is the dipolar relaxation time of the solute [described further in the Molecular Rotation section of the SI], and $\mathrm{T}$ is temperature. The function $f(\omega \theta)$ describes the variation in experimental sensitivity due to the correlation between the microwave frequency and the frequency of the dipole's relaxation.

$$
f(\omega \theta)=\frac{(\omega \theta)^{2}}{1+(\omega \theta)^{2}}
$$


The electronic component of the real permittivity is a function of the solute's electronic polarizability $\left(\alpha_{e}\right)$.

$$
\varepsilon_{E}^{\prime}=\frac{(\varepsilon(0)+2)(\varepsilon(\infty)+2)}{9 \varepsilon_{0}} \alpha_{e} N
$$

In contrast to the real part, the imaginary part of the complex permittivity is only a function of the dipole moment and looks similar to equation (3), however, the denominator term $(\omega \theta)$ is not squared.

$$
\varepsilon^{\prime \prime}=\frac{(\varepsilon(0)+2)(\varepsilon(\infty)+2)}{27 \varepsilon_{0} k_{B} T} \frac{\mu^{2}}{\omega \theta} N f(\omega \theta)
$$

\section{Ground-state dielectric-loss}

We calculate the ground-state dipole moment of a solute molecule by performing a series of measurements of $\varepsilon^{\prime \prime}$ as a function of solute concentration. Rewriting equation (6) to reflect this experiment yields the following equation:

$$
\Delta \varepsilon^{\prime \prime}=\frac{(\varepsilon(0)+2)(\varepsilon(\infty)+2)}{27 \varepsilon_{0} k_{B} T} \frac{\mu_{G S}^{2}}{\omega \theta} \Delta N f(\omega \theta)
$$

Where now the solute concentration changes $(\Delta N)$ thus changing $\Delta \varepsilon^{\prime \prime}$ and the solvent's contribution subtracts out. Dividing both sides by $\Delta N$ in equation (7), provides an expression for the slope of this concentration-dependent study.

$$
\text { slope }=\frac{\Delta \varepsilon^{\prime \prime}}{\Delta N}=\frac{(\varepsilon(0)+2)(\varepsilon(\infty)+2)}{27 \varepsilon_{0} k_{B} T} \frac{\mu_{G S}^{2}}{\omega \theta} f(\omega \theta)
$$

Rearranging equation (8) gives the expression for the ground-state dipole moment.

$$
\mu_{G S}=\sqrt{\frac{27 \varepsilon_{0} k_{B} T}{(\varepsilon(0)+2)(\varepsilon(\infty)+2)} \frac{\omega \theta}{f(\omega \theta)}\left[\frac{\Delta \varepsilon^{\prime \prime}}{\Delta N}\right]}
$$

Once the slope of the $\Delta \varepsilon^{\prime \prime}$ vs. concentration has been measured, the only remaining unknown in this equation is the dipolar rotational relaxation of the solute. We have implemented a numerical simulation package in Python which provides accurate values for the dipolar rotational relaxation time using the molecular structure, solvent viscosity, solvent dielectric, and temperature as input parameters [described further in the Molecular Rotation section of the SI] enabling accurate dipole moment measurements without the need for carefully selected standards or outside experiments as was the case in the past. ${ }^{41,44}$ Due to experimental sensitivity constants, we are unable to use this same technique in order to measure the ground-state polarizability with much accuracy without going to unacceptably high solute concentrations.

\section{Excited-state transient dielectric-loss}

Photoexcitation is used to excite the sample and study the dipole moment and polarizability of the excited-states. In this case, equation 3 describing the dipole component of the real permittivity becomes:

$$
\Delta \varepsilon_{D}^{\prime}(t)=\frac{(\varepsilon(0)+2)(\varepsilon(\infty)+2)}{27 \varepsilon_{0} k_{B} T} \frac{\mu_{*}^{2}-\mu_{G S}^{2}}{(\omega \theta)^{2}} N_{*}(t) f(\omega \theta)
$$

Where $N_{*}(t)$ is the excited-state solute concentration in molecules $/ \mathrm{m}^{3}$ as a function of time due to the sample's excited-state kinetics, and $\mu_{*}^{2}$ is the excited-state dipole moment. Equation (5) which describes the polarizability component of the real permittivity becomes:

$$
\Delta \varepsilon_{E}^{\prime}(t)=\frac{(\varepsilon(0)+2)(\varepsilon(\infty)+2)}{9 \varepsilon_{0}} \Delta \alpha_{e} N_{*}(t)
$$


Change in electronic polarizability is related to the polarizability volume $\left(\Delta V_{p}\right)$ which qualitatively describes the localization volume of a molecular excited-state. ${ }^{47}$

$$
\Delta V_{p}=\frac{\Delta \alpha_{e}}{4 \pi \varepsilon_{0}}
$$

Finally, the imaginary component of the complex permittivity becomes the following equation.

$$
\Delta \varepsilon^{\prime \prime}(t)=\frac{(\varepsilon(0)+2)(\varepsilon(\infty)+2)}{27 \varepsilon_{0} k_{B} T} \frac{\mu_{*}^{2}-\mu_{G S}^{2}}{\omega \theta} N_{*}(t) f(\omega \theta)
$$

For transient measurements, we fit a global kinetic model to our data (detailed in the Fitting TRDL Transients section of the SI) in order to get an excited-state concentration $\left(N_{*}(t)\right)$ for each kinetic component. Then, the $\Delta \varepsilon^{\prime}$ and $\Delta \varepsilon^{\prime \prime}$ values that relate to those respective components are used to calculate the various changes in dipole moment and molecular polarizability volume. The absolute value of the excited-state dipole moment can then be calculated knowing the ground-state dipole moment.

Thermal artifacts are easily measured in dielectric-loss spectroscopy due to its high sensitivity. These arise from transient changes in the dielectric properties of the solvent as a function of local temperature. Since the TRDL signal is proportional to the concentration of the excited species, small thermal changes in the solvent easily overwhelm larger changes in the solute properties. To minimize this, TRDL must be performed in low dielectric-constant solvents so that thermally-induced changes in its dielectric constant also remain small. For all of the work in this paper, 1,4-dioxane has been used as it has shown no evidence of thermal artifacts in TRDL transients.

\section{Validating our methods using $\mathrm{N}, \mathrm{N}$-dimethylaminobenzonitrile}

A donor-acceptor molecule, N,N-dimethylaminobenzonitrile, was used to test the validity of our COMSOL simulations, dipolar relaxation time calculations, and overall analysis. DMABN has been extensively studied because of it's intramolecular charge-transfer (ICT) excited-state and resulting dual-emission; in particular, John Warman has reported on its kinetics, ground-state dipole moment and excited-state dipole moments using dielectric-loss spectroscopy, making it an ideal reference compound for our work. ${ }^{48-51}$

DMABN has two singlet states in equilibrium, a locally excited-state (LE) and the intramolecular charge transfer state (ICT). The LE state has a dipole moment that is only slightly larger than that in the ground-state at $9.7 \mathrm{D}$; whereas, the ICT state's dipole moment is significantly larger than the ground-state at $15.1 \mathrm{D} .{ }^{52}$ The initial LE-ICT singlet state relaxes through a triplet state that has a dipole moment approximately equal to that of the LE state, with its inter-system crossing yield being correlated to the solvent's polarity. The CT state is stabilized by the solvent's polarity as well, thus the ratio of CT:LE is higher in polar solvents and the CT state's dipole moment dominates the TRDL signal at early times when the singlet state is evolving.

Figure 2(a) shows a plot of imaginary permittivity as a function of DMABN concentration in 1,4-dioxane. Using the slope of the linear fit, equation (9), and a $\theta$ of $33.4 \mathrm{ps,} \mathrm{we} \mathrm{found} \mathrm{the} \mathrm{ground-state} \mathrm{dipole} \mathrm{moment} \mathrm{of} \mathrm{DMABN} \mathrm{to} \mathrm{be} \mathrm{6.2} \mathrm{D.} \mathrm{This} \mathrm{is} \mathrm{in}$ close agreement with the ground-state value for DMABN reported by Warman using TRDL: 6.6 D. This result demonstrates the accuracy and precision with which we can measure the ground-state dipole moment of a molecule in solution using our instrument and data analysis methods, and validates the calculations used to determine $\theta$ (described in the Molecular Rotation section of the SI). 


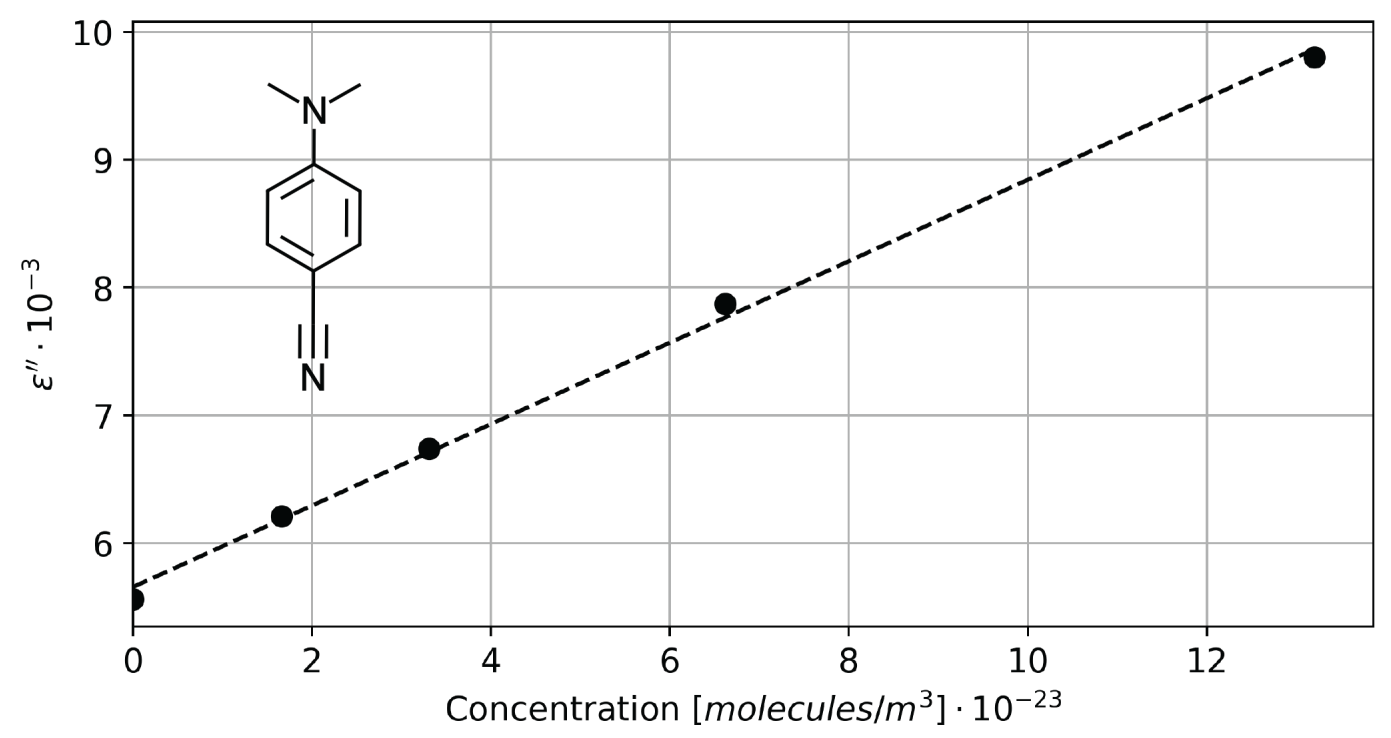

(a)

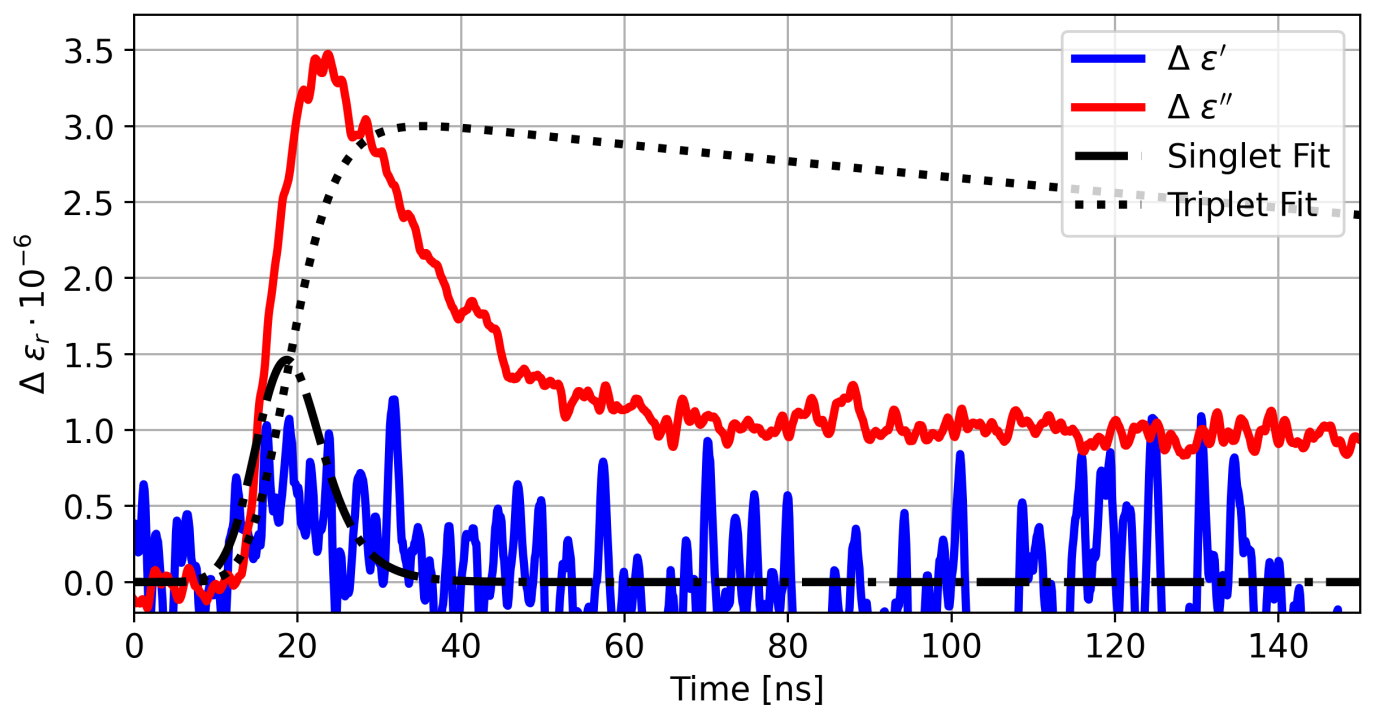

(b)

Figure 2. (a) Ground-state measurement of the imaginary permittivity as a function of DMABN concentration in 1,4-dioxane with the structure of DMABN as the inset. A linear fit of the form $y=8.249 \cdot 10^{-27} x+4.05 \cdot 10^{-3}$ is used to extract the change in permittivity per DMABN molecule, and extract a ground-state dipole moment of $6.2 \mathrm{D}$ using equation (9). (b) complex permittivity transients for DMABN (red and blue) and the kinetic fitting results (black), showing the singlet and triplet species trajectories. The global fit lines to the real and imaginary transients are omitted for clarity. $300 \mathrm{~nm}$ excitation at $5.45 \cdot 10^{15} \mathrm{~cm}^{-} 2,7 \mathrm{~ns}$ FWHM pulse, $[\mathrm{DMABN}]=0.15 \mathrm{mM}$ in dioxane

Figure 2(b) shows the transient kinetics for $0.15 \mathrm{mM}$ DMABN in 1,4-dioxane upon photoexcitation at $300 \mathrm{~nm}$. Here, the real (blue) and imaginary (red) components of the of the transient change in permittivity are separated using the procedure described in the Fitting COMSOL Models to Data and the Complex K-Factor section of our SI, giving quantitative values for $\Delta \varepsilon_{r}$. Notably, the noise level here is $\sim 100 \mathrm{ppb}$ in $\varepsilon_{r}$ after averaging fewer than 100 laser shots (limited by the photostability of $D M A B N)$. The transient kinetics observed are similar to that reported by Warman when taking into account the differences in instrument response. Indeed, the kinetics are fit using an identical model to that employed by Warman, with certain key parameters fixed from his prior work: sequential conversion of the LE+ICT singlet to the triplet state in competition with 
ground-state recovery. ${ }^{52}$ The black traces in Figure 2(b) show the kinetic trajectories assigned to the singlet (solid) and triplet (dashed) states. The conversion between the singlet and triplet states takes place too fast $\left(\sim 10^{10} s^{-1}\right)$ for a TRDL experiment to properly constrain the kinetic fit, and we use TRPL results from the literature to fix this timescale in our model. ${ }^{52-54}$ Likewise, the TRDL experiment does not directly observe conversion of the singlet LE and ICT states to the ground-state in competition with intersystem crossing, and we fix the triplet yield based on prior results as well. ${ }^{54}$ Thus, the only free fit parameters in our global kinetic model (over real and imaginary signals) is the triplet state lifetime and the change in $\varepsilon_{r}$ per molecule. The rate constants associated with each state are summarized in (see Supplementary Table S3), and the extracted values for the transient dipole moments for the ground, singlet, and triplet excited-states are summarized in table 1. In agreement with the previous literature: (1) the singlet state of DMABN is dominated by the large dipole moment associated with the ICT state in 1,4-dioxane, and (2) the obtained triplet state dipole is substantially less than that of the singlet state.

Table 1. Dipole measurement literature comparison of DMABN in 1,4 -dioxane. ${ }^{52,54}$

\begin{tabular}{|l|c|c|c|}
\hline & Experiment & Literature & Agreement \\
\hline$\mu_{G S}$ & $6.2 \pm 0.2 \mathrm{D}$ & $6.6 \mathrm{D}$ & $94.1 \%$ \\
$\Delta \mu_{S}$ & $6.1 \pm 0.2 \mathrm{D}$ & $8.5 \mathrm{D}$ & $72.0 \%$ \\
$\Delta \mu_{T}$ & $1.78 \pm 0.05 \mathrm{D}$ & $3.1 \mathrm{D}$ & $57.5 \%$ \\
\hline
\end{tabular}

The relatively weaker agreement (relative to literature) in the absolute excited-state dipole moments we calculate compared to the ground-state most likely arises from the difficulty in ascertaining the excited-state concentration, both in our case and in past measurements. Since the calculation of the transient dipole moment is coupled to the excited-state solute concentration, the accuracy of estimating this concentration introduces error into the resultant dipole value in cases such as this where much of the dynamics are instrument-response limited. Warman et. al. relied on internal actinometry for estimating the excited-state concentration and parallel TRPL measurements to fix kinetic parameters that were not measurable via TRDL. We use careful calibration of light absorption in our EPR-tube sample configuration and excited-state density simulations that account for saturable absorption effects [discussed in section Excitation Density Calculations in the SI]. Additionally, we observed sample degradation from laser excitation, which was minimized but possibly not eliminated, by handling all samples in a nitrogen glove box, limiting our analysis to averaging the first 100 transients, and refreshing sample intermittently throughout the measurement. The good agreement we obtain for the singlet state shows that these methods are effective, but the rather large discrepancy for the triplet dipole moment measurement suggests that the triplet yield may be substantially lower in our hands than the value found previously, which is fixed in our kinetic model at the literature value. ${ }^{54}$

\section{Contact-ion Pairing and Transient Dipole Moments in $\left[\operatorname{Ir}\left[\mathbf{d F}\left(\mathbf{C F}_{3}\right) \mathbf{p p y}\right]_{2}(\mathbf{d t b p y})\right] \mathrm{X}$}

Having established the accuracy of our experimental methods via the well-studied ICT excited-state of DMABN, we turn to the more complex topic of the cationic photoredox catalysts $\left[\operatorname{Ir}\left[d F\left(C F_{3}\right) p p y\right]_{2}(d t b p y)\right] X($ abbreviated: $\operatorname{Ir}[t B u]-X)$. Here, we expect a metal-to-ligand charge transfer (MLCT) state that is analogous to the ICT state of DMABN, but the presence of multiple ligands, large-spin-orbit coupling due to $\operatorname{Ir}(\mathrm{III})\left(\xi_{c, I r}=3909 \mathrm{~cm}^{-1} \mathrm{vs} \text {. } \xi_{c, s o c, R u(I I)}=990 \mathrm{~cm}^{-1}\right)^{55}$, and ion pairing in a low dielectric constant solvent introduce new and unexpected dynamics. Below, we show that the highly mixed excited-states of our energetically similar ligands manifests as charge transfer processes from $d F\left(C F_{3}\right) p p y$ to $d t b p y$ on the ns timescale. Meanwhile, contact-ion pairing introduces an intermolecular dipole moment between the two ionic species that dramatically changes the dipole of the excited-state through additional nuclear reorganization. These latter two effects vanish for a more weakly bound anion, whilst a flip-flopping inter-ligand charge transfer behavior at early times is consistent in both. 


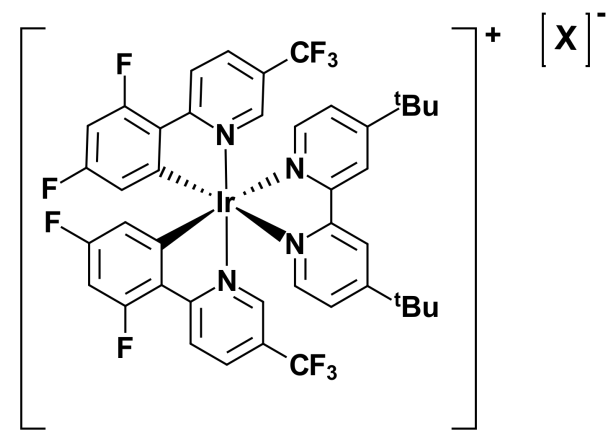

(a)

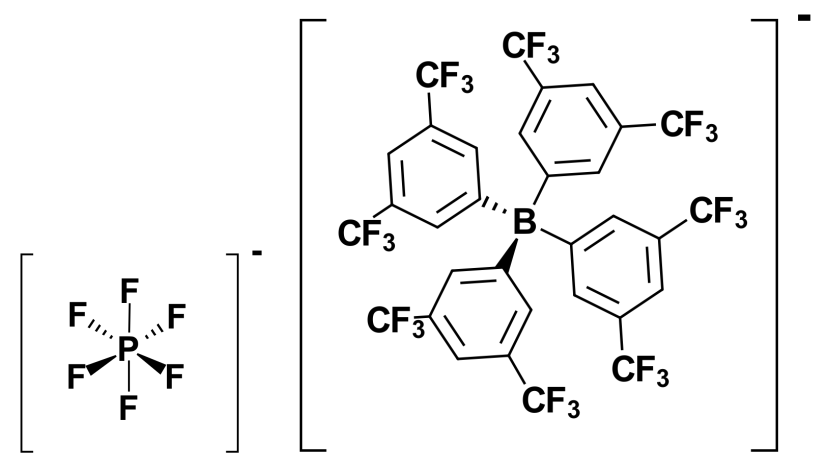

(c)

Figure 3. Structures of the iridium cation (a) $\left[\operatorname{Ir}\left[d F\left(C F_{3}\right) p p y\right]_{2}(d t\right.$ tby $\left.)\right] X$ with anion $\mathrm{X}$ being (b) $\mathrm{X}=P F_{6}^{-}$(c) $\mathrm{X}=B A r_{4}^{F-}$

\section{lon Pairing in the ground-state}

We control ion pairing in $\operatorname{Ir}[t B u]-X$ in 1,4-dioxane by tuning the size of the anion $\left(X^{-}\right)$. Using $P F_{6}^{-}$as the counter ion is expected to result in contact-ion pairing in 1,4-dioxane due to its small size in relation to $\left[\operatorname{Ir}\left[d F\left(C F_{3}\right) p p y\right]_{2}(d t b p y)\right]^{+}$ (abbreviated: $\operatorname{Ir}[t \mathrm{Bu}]^{+}$), whereas using the much bulkier tetrakis[3,5-bis(trifluoromethyl)phenyl]borate ${ }^{1-}\left(B A r_{4}^{F-}\right)$ should shift the dissociation equilibrium so that contact-ion pairs no longer form, as $\operatorname{Ir}[t B u]^{+}$and $B A r_{4}^{F-}$ are relatively the same size. As with DMABN, measuring the characteristics of the microwave cavity as a function of the $\operatorname{Ir}[t B u]-X$ concentrations allows us to obtain their ground-state dipole moments. However, an additional complexity in this context is that it is necessary to make an assumption about whether contact-ion pairing takes place in order to calculate the rotational relaxation time of the complex, which can change significantly when the ion pair rotates as a unit. The approach we take here is to test each possibility (contact-paired vs. not) and observe whether the dipole moment we calculate is consistent with basic chemical theory and literature calculations. ${ }^{56-58}$ This provides an excellent method for assessing ion pairing in the ground-state of these complexes. The results of these elementary calculations are displayed in table 2.

Table 2. Predicted ground-state dipole moment between the iridium metal center and the anion's center using basic chemical theory ( $\mu=d \cdot q$; where $\mathrm{d}$ is distance between charges and $\mathrm{q}$ is the elementary charge) for $\operatorname{Ir}[t B u]-P F_{6}$ and $\operatorname{Ir}[t B u]-B A r_{4}^{F}$ assuming only contact-ion pairing.

\begin{tabular}{|l|c|c|}
\hline & Distance between $I r^{+}$and $X^{-}$ & $\mu_{\text {Predicted }}$ \\
\hline$I r[t B u]-P F_{6}$ & $5.7 \AA$ & $27.4 \mathrm{D}$ \\
\hline$I r[t B u]-B A r_{4}^{F}$ & $13.0 \AA$ & $62.4 \mathrm{D}$ \\
\hline
\end{tabular}




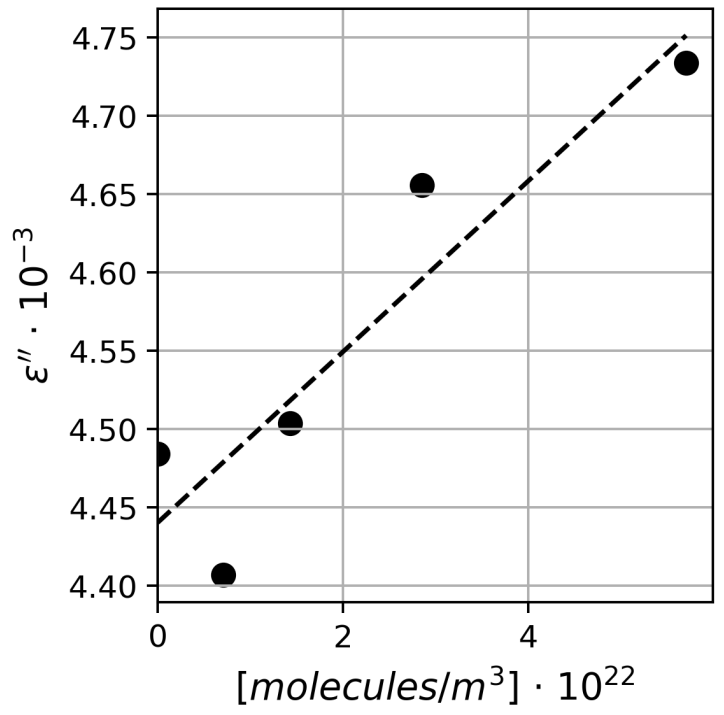

(a)

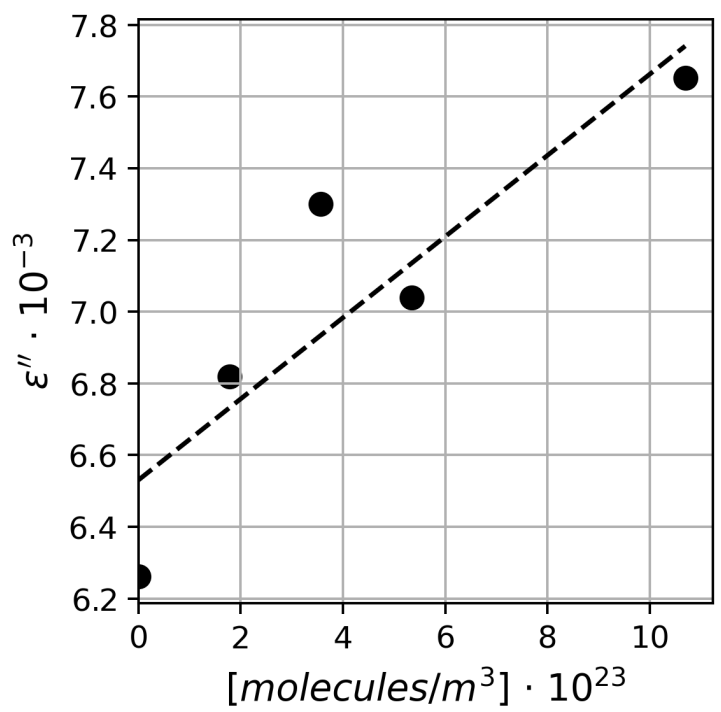

(b)

Figure 4. (a) Ground-state measurement of the imaginary permittivity as a function of $\operatorname{Ir}[t \mathrm{Bu}]-P F_{6}$ concentration in 1,4-dioxane. A linear fit of the form $\varepsilon^{\prime \prime}=5.46 \cdot 10^{-27} x+4.44 \cdot 10^{-3}$. (b) ground-state measurement of the imaginary permittivity as a function of $\operatorname{Ir}[t B u]-B A r_{4}^{F}$ concentration in 1,4-dioxane. A linear fit of the form in dioxane. A linear fit gives the form $\varepsilon^{\prime \prime}=1.13 \cdot 10^{-27} x+6.53 \cdot 10^{-3}$.

When considering the ligand framework of $\operatorname{Ir}[t \mathrm{Bu}]^{+}$, a ground-state dipole moment is expected on grounds of both symmetry and formal charge distribution. However, cyclometalation of $\operatorname{Ir}(\mathrm{III})$ with $d F(C F)_{3}$ ppy ligands produces a highly mixed HOMO $\left(I r_{d}-d F(C F)_{3} p p y\right)$ that lies relatively close to the metal. ${ }^{12,59}$ This bonding environment implies that the ground-state intramolecular dipole in $\operatorname{Ir}[t \mathrm{Bu}]^{+}$should be relatively small. In contrast, the apparent dipole moment resulting from a contact-ion pair interaction is expected to be large, due to the relatively large separation between the ionic charge centers and the fact that the ions rotate as a single unit in solution. Directly measured dipole moments of $\left[\operatorname{Ir}\left(\mathrm{C}^{\wedge} \mathrm{N}\right)_{2}\left(\mathrm{~N}^{\wedge} \mathrm{N}\right)\right]^{+}$complexes have never been reported to our knowledge, either in the ground or excited-states. ${ }^{10,19-21,23,31,33-36,56-58}$

Using the slope from $\varepsilon$ " vs the concentration of $\operatorname{Ir}[t B u]-P F_{6}$ in 1,4-dioxane (figure 4(a)), equation (9), and a $\theta_{\text {paired }}$ of 70.5 ps (calculated assuming contact-ion pairing as described in the Molecular Rotation section of the SI) we found the ground-state dipole moment of $\operatorname{Ir}[t B u]-P F_{6}$ to be $10.7 \mathrm{D}$. If we assume loose or no ion pairing, the rotation time is modified to $68.26 \mathrm{ps}$ and the calculated dipole moment is reduced to $10.6 \mathrm{D}$, only a small change occasioned by the very compact size of $\mathrm{PF}_{6}^{-}$. In both cases, the magnitude of the ground-state dipole is substantially larger than what we would expect for the intramolecular ground-state dipole moment of just $\operatorname{Ir}[t \mathrm{Bu}]^{+}\left(\sim 5.0 \mathrm{D}\right.$, based on that of $\operatorname{Ir}\left(\right.$ ppy) ${ }_{3}$ (see SI section Non-ionic Iridium(III) Complex)). Yet, the calculated value is still smaller than we expect for a contact-ion pair $\operatorname{Ir}[t B u]-P F_{6}(27.4 \mathrm{D})$. We posit three primary explanations: first, that the inter- and intra- molecular dipoles partially cancel in a contact-ion pair that self-organizes to minimize electrostatic energy, as depicted in Figure 5a. Second, that the small $P F_{6}^{-}$anion may lie $\sim 2.5 \AA$ closer to the positive charge center than expected $(27.4-5.0=22.4 \mathrm{D}$, integer charge separation produces a dipole moment of 4.8 D/Å), interdigitating with the ligand shell. Third, that contact ion pair is likely to be in equilibrium with solvent-separated pairs, which would reduce the average dipole moment that we measure.

An excellent test of these ideas is comparison with results for the more weakly pairing anion $B A r_{4}^{F-}$. Using the slope from $\varepsilon$ " vs. the concentration of $\operatorname{Ir}[t B u]-B A r_{4}^{F}$ (figure 4(b)), equation (9), and a $\theta_{\text {unpaired }}$ of 68.3 ps (calculated assuming loose ion pair association); we found the ground-state dipole moments of $\operatorname{Ir}[t B u]-B A r_{4}^{F}$ to be $4.82 \mathrm{D}$, consistent with our expectations for the range of possible dipole moment of $\operatorname{Ir}[t \mathrm{Bu}]^{+}$. If we assume contact-ion pairing on the other hand, we obtain a much larger dipolar relaxation time of $\theta_{\text {paired }}=367 \mathrm{ps}$ due to the large size of the $B A r_{4}^{F-}$ anion. Using this value we calculate a dipole moment of $10.8 \mathrm{D}$, which in this case is far too small to be consistent with the large intermolecular dipole moment expected for a contact-ion pair of $\operatorname{Ir}[t B u]-B A r_{4}^{F}$, even when the anti-parallel vector sum of the intramolecular and intermolecular dipole moments and similar charge displacements are considered. This, combined with the consistency of the unpaired dipole we measure here with that of $\operatorname{Ir}(p p y)_{3}$ (see Supplementary Fig. S11), leads us to conclude that contact-ion pairs are absent for 
$\operatorname{Ir}[t B u]-B A r_{4}^{F}$. Thus, our data is consistent with the idea that a majority of $\operatorname{Ir}[t B u]-P F_{6}$ species in 1,4-dioxane form contact-ion pairs that self-organize to minimize the overall dipole moment, while the majority of $\operatorname{Ir}[t B u]-B A r_{4}^{F-}$ species exist as either solvent-separated ion pairs or dissociated ions, even in 1,4-dioxane.

These assignments are supported by subtle differences in absorbance and steady-state emission spectra we observe for $\operatorname{Ir}[t B u]-P F_{6}$ vs $\operatorname{Ir}[t B u]-B A r_{4}^{F}$ (See SI sections: Absorption and emission spectroscopy and $\left[\operatorname{Ir}\left(C^{\wedge} N\right)_{2}\left(N^{\wedge} N\right)\right] X$ Electronic Structure). The dipole moment values we obtain are also broadly consistent with prior solvatochromism measurements for $\left[\operatorname{Ir}\left(\mathrm{C}^{\wedge} \mathrm{N}\right)_{2}\left(\mathrm{~N}^{\wedge} \mathrm{N}\right)\right] \mathrm{Cl}$ complexes where $\left(\mathrm{C}^{\wedge} \mathrm{N}\right)=$ ppy or benzo[h]quinoline $($ bzq $)$, and $\left(\mathrm{N}^{\wedge} \mathrm{N}\right)=$ bpy or 1,10 -phenanthroline $($ bpy $\left.)\right) .{ }^{56}$ In this study, the ground and excited-state dipole moments were determined from absorption and emission solvatochromism data in 17 solvents spanning the polarity spectrum, but neglecting to account for ion pairing behavior. Thus, in low dielectric solvents, the dipole moment they observed should be characteristic of the ion-paired species $\left[\operatorname{Ir}\left(\mathrm{C}^{\wedge} \mathrm{N}\right)_{2}\left(\mathrm{~N}^{\wedge} \mathrm{N}\right)\right] \mathrm{Cl}$, whilst in high dielectric solvents it most likely represents that of the unpaired species. We conjecture that their measured value $\left(\mu_{\text {Lit }}=6.7\right.$ D), represents an average of these two extremes, and compares favorably with an average of the dipole moments we find for $\operatorname{Ir}[t B u]-P F_{6}$ and $\operatorname{Ir}[t B u]-B A r_{4}^{F}\left(\mu_{A v g}=7.7 \mathrm{D}\right)$.

Figure 5 illustrates the ion-pairing behavior we propose for the ground-state without contact-ion pairing (5(a)) and with contact-ion pairing (5(b)). If the ion pair is not in contact, the overall dipole moment measured using dielectric-loss will be equal to just the intramolecular dipole moment (purple). However, in the presence of contact-ion pairing, the overall dipole moment measured using dielectric-loss will be equal to the vector sum (equation (14)) of the intramolecular dipole moment (purple) and the intermolecular dipole moment (yellow). Dielectric-loss can only measure ion pairs that are bound sufficiently tightly for the pair to tumble as a single molecular unit in solution. In any situation where each complex can tumble separately the measured dipole moment will revert to the intramolecular component depicted in Fig. 5(a), even if the ions remain paired in a looser solvent-separated fashion. ${ }^{23}$

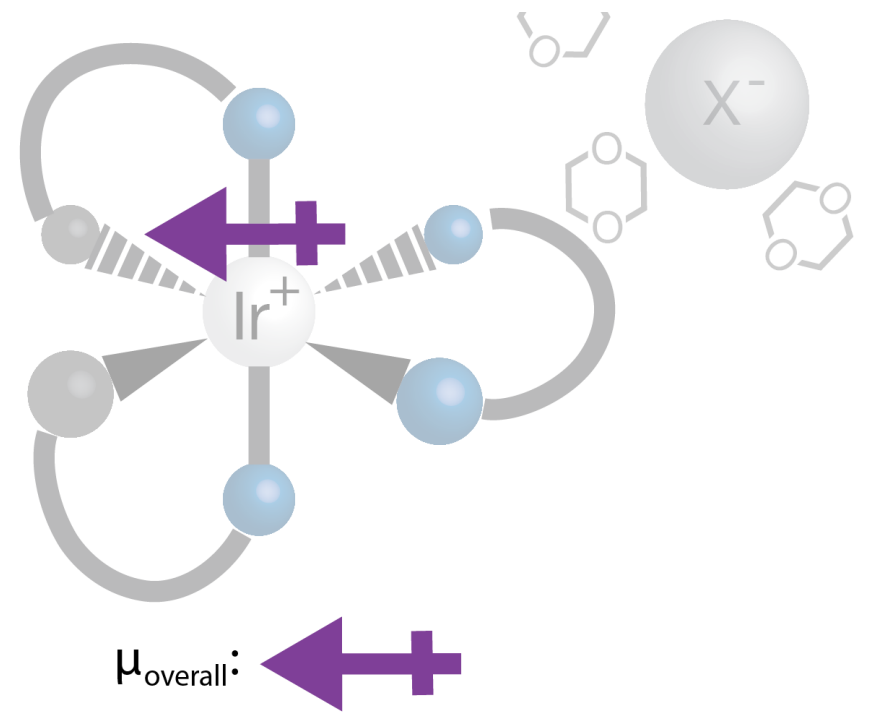

(a)

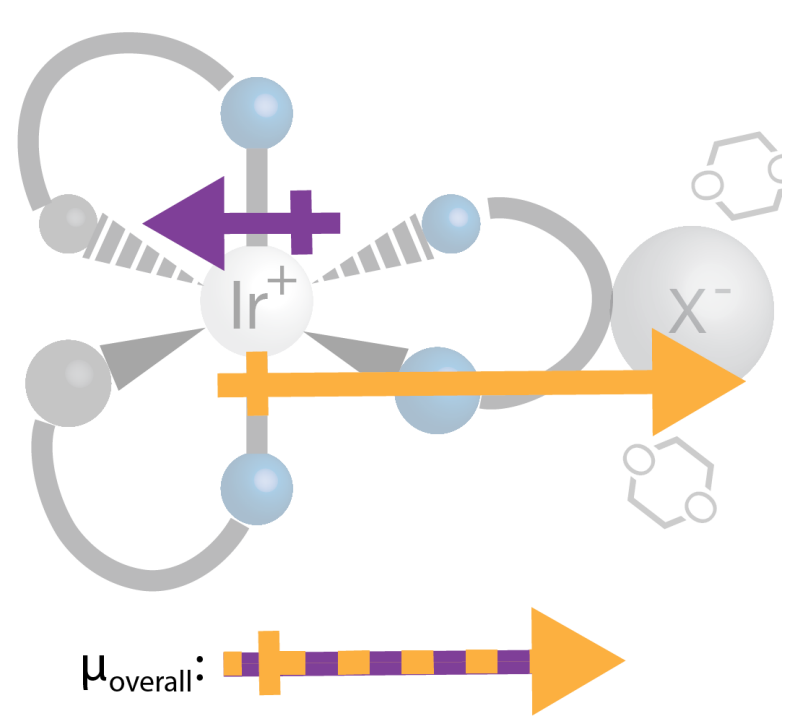

(b)

Figure 5. Overall dipole moment showing the intramolecular dipole (purple) and the intermolecular dipole (yellow). (a) Ground-state dipole configuration for a complex without contact-ion pairing, as predicted in the case of $\operatorname{Ir}[\operatorname{tBu}]-B A r_{4}^{F}$, showing that the signal observed using dielectric-loss will be the same as the intramolecular dipole moment of $\operatorname{Ir}[\mathrm{tBu}]^{+}$. (b)

Ground-state dipole configuration for a contact-ion paired complex, as predicted in the case of $\operatorname{Ir}[t B u]-P F_{6}$, showing the overall dipole moment observed by dielectric-loss is the vector sum (dashed arrow) of the intramolecular dipole moment of $\operatorname{Ir}[\operatorname{tBu}]^{+}$ and the intermolecular dipole moment between $\operatorname{Ir}[t B u]^{+}$and $X^{-}$.

$$
\mu_{\text {overall }}=\left|\vec{\mu}_{\text {intra }}+\vec{\mu}_{\text {inter }}\right|
$$


Table 3. Ground-state dipole moments for $\operatorname{Ir}[t B u]-P F_{6}$ and $\operatorname{Ir}[t B u]-B A r_{4}^{F}$ assuming (a) separation-ion pairing and (b) contact-ion pairing.

\begin{tabular}{|l|c|c|c|c|c|}
\hline & $\varepsilon^{\prime \prime} /$ molecule & $\theta^{a}$ & $\mu_{G S}^{a}$ & $\theta^{b}$ & $\mu_{G S}^{b}$ \\
\hline $\operatorname{Ir}[t B u]-P F_{6}$ & $5.45 i \cdot 10^{-27}$ & $68.3 \mathrm{ps}$ & $10.6 \pm 2.7 \mathrm{D}$ & $70.5 \mathrm{ps}$ & $10.7 \pm 2.7 \mathrm{D}$ \\
\hline $\operatorname{Ir}[t \mathrm{Bu}]-B A r_{4}^{F}$ & $1.13 i \cdot 10^{-27}$ & $68.3 \mathrm{ps}$ & $4.8 \pm 1.4 \mathrm{D}$ & $367 \mathrm{ps}$ & $10.8 \pm 3.2 \mathrm{D}$ \\
\hline
\end{tabular}

\section{Transient Dipole Moment}

fp-TRDL was performed on both complexes to study how their dipole moments change after photoexcitation. Having observed dominant contact ion pairing in the ground-state of $\operatorname{Ir}[t B u]-P F_{6}$ and minimal contact ion pairing in $\operatorname{Ir}[t B u]-B A r_{4}^{F}$, we expect to see similar changes in their measured excited-state dipole moments. Transient data for both complexes are shown in Fig. 6 (a) $\left(X^{-}=P F_{6}^{-}\right)$and (b) $\left(X^{-}=B A r_{4}^{F}\right)$. The data obtained were collected and separated into their complex permittivity components as detailed in the Fitting COMSOL Models to Data and the Complex K-Factor section of the SI. Both complex's kinetics were fit with a global two-Species sequential kinetic model similar to that used for DMABN. Here, however, there is less of a clear a-priori basis for assigning the identity of these kinetically identified Species from TRDL measurements. We simply designate the fast, early-time component as Species A and the slower, later-time component as Species B for now. The rate constants from the kinetic fits and the absolute dipole moments are summarized in table 4. 


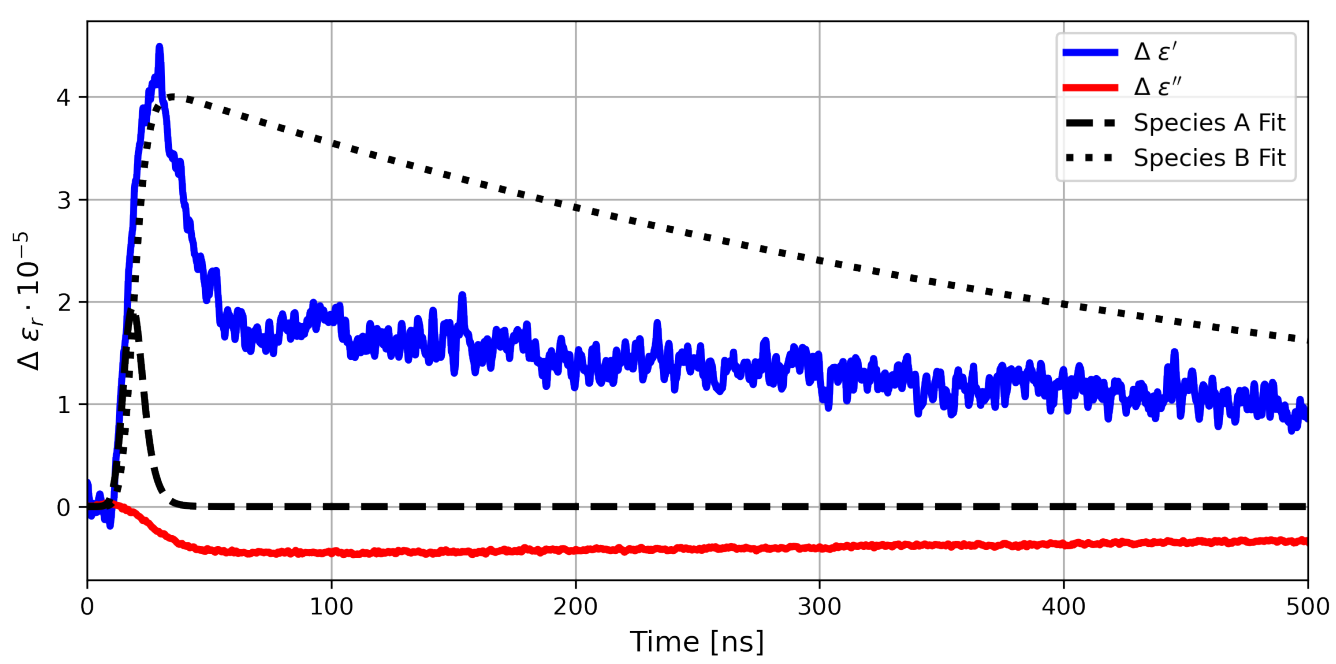

(a)

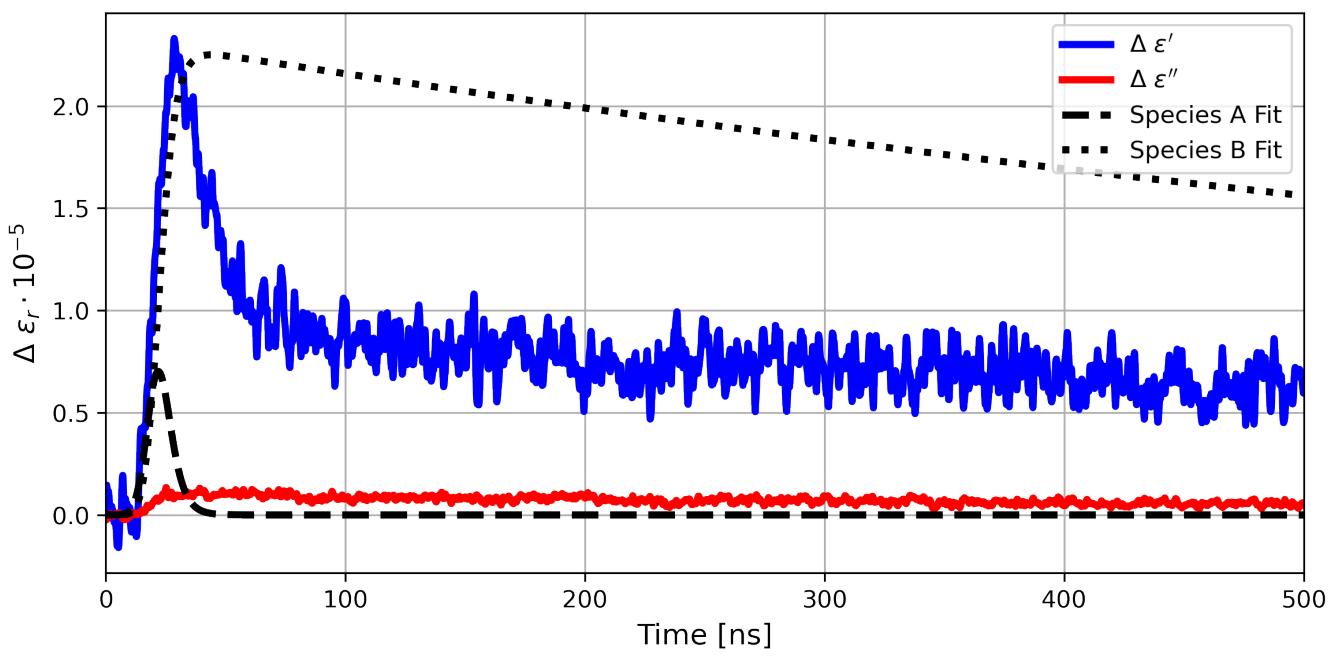

(b)

Figure 6. fp-TRDL to studies of the excited-state kinetics separating the transients into real (blue) and imaginary (red) permittivities with the kinetic fits corresponding to the early-time Species A and later-time Species B. (a) fp-TRDL transient for $\operatorname{Ir}[t B u]-P F_{6}$ at a concentration of $0.23 \mathrm{mM}, 410 \mathrm{~nm}$ excitation at $\sim 4.71 \cdot 10^{16} \mathrm{~cm}^{-2}, 7 \mathrm{~ns}$ FWHM pulse. The negative change in the imaginary permittivity is a result of ion pairing. (b) fp-TRDL transient for $\operatorname{Ir}[t B u]-B A r_{4}^{F}$ at a concentration of $0.36 \mathrm{mM}$, $410 \mathrm{~nm}$ excitation at $\sim 1.06 \cdot 10^{16} \mathrm{~cm}^{-2}, 7 \mathrm{~ns}$ FWHM pulse. The positive change in imaginary permittivity arises from measuring the intramolecular dipole moment without the influence of a contact-counter ion. 
Table 4. Summary of $\operatorname{Ir}[t B u]-P F_{6}$ and $\operatorname{Ir}[t B u]-B A r_{4}^{F}$ parameters from experimental data.

\begin{tabular}{|c|c|c|c|c|c|}
\hline & State & $\begin{array}{c}\varepsilon_{r} / \text { molecule } \\
\left(10^{-27}\right)\end{array}$ & $\begin{array}{c}\mu \\
(\mathrm{D})\end{array}$ & $\begin{array}{c}\Delta V_{p} \\
\left(\AA^{3}\right)\end{array}$ & $\begin{array}{c}\text { Rate constant } \\
\left(s^{-1}\right)\end{array}$ \\
\hline \multirow{3}{*}{$\operatorname{Ir}[t \mathrm{~B} u]-P F_{6}$} & GS & $5.46 i$ & $10.7 \pm 2.7$ & - & - \\
& $\mathrm{A}$ & $\Delta(21.7-0.189 i)$ & $10.9 \pm 2.7$ & 858 & $2.78 \cdot 10^{8}$ \\
& $\mathrm{~B}$ & $\Delta(1.81+0.535 i)$ & $10.2 \pm 2.6$ & 77.4 & $1.38 \cdot 10^{6}$ \\
\hline \multirow{3}{*}{$r[\mathrm{tBu}]-B A r_{4}^{F}$} & $\mathrm{GS}$ & $1.13 i$ & $4.8 \pm 1.4$ & - & - \\
& $\mathrm{A}$ & $\Delta(21.3-0.886 i)$ & $6.4 \pm 1.9$ & 833 & $2.78 \cdot 10^{8}$ \\
& $\mathrm{~B}$ & $\Delta(1.64-0.158 i)$ & $5.2 \pm 1.6$ & 63.5 & $8.90 \cdot 10^{5}$ \\
\hline
\end{tabular}

While TRDL measurements can't directly report on the identity of Species A and B, the obtained time constants and dipole measurements are interpreted with respect to the literature on similar $\operatorname{Ir}(\mathrm{III})$ species to help elucidate the photoexcitation mechanism. Species A for both $\operatorname{Ir}[t B u]-P F_{6}$ and $\operatorname{Ir}[t B u]-B A r_{4}^{F}$ displays nearly instrument-response limited kinetics and is associated with a large increase in $\Delta \varepsilon^{\prime}$ which is a function of the polarizability volume and the dipole moment. Since this feature of Species A is present in both complexes, it is most likely a property of $\operatorname{Ir}[t B u]^{+}$, and not influenced by differences in ion pairing behavior. Moreover, the change in $\Delta \varepsilon^{\prime \prime}$ is much smaller than $\Delta \varepsilon^{\prime}$, indicating that the major contribution to $\Delta \varepsilon^{\prime}$ is a change in the polarizability volume. Two mechanisms can contribute to a change in polarizability volume; the electron cloud increasing in volume, or a resonance structure where a dipole moment flips between resonances much faster than the frequency of the microwave electric field ( $<100$ ps period). Since the $d F\left(C F_{3}\right)$ ppy-based LUMO+1 and $d t b p y$-based LUMO are energetically similar in $\operatorname{Ir}[t B u]^{+}$(See SI, $\left[\operatorname{Ir}\left(C^{\wedge} N\right)_{2}\left(N^{\wedge} N\right)\right] X$ Electronic Structure), we conclude that the change in polarizability volume is due to ligand-ligand charge transfer (LLCT) dynamics described by the dipole moment shifting between the $d F\left(C F_{3}\right) p p y$ and dtbpy ligand in the excited-state. This interpretation of the large $\Delta \varepsilon^{\prime}$ signal is consistent with previous reports on similar complexes indicating that large changes in dipole upon photoexcitation result from substantial geometric distortion in the $M L C T_{b p y}$ excited-states due to LLCT. ${ }^{19,20,56,58,60,61}$ Moreover, we observe at least two emissive bands in the emission profile of both $\operatorname{Ir}[t B u]-P F_{6}$ and $\operatorname{Ir}[t B u]-B A r_{4}^{F}$ (See SI, Absorbance and emission spectroscopy). The origin of multiple emission bands in $\left[\operatorname{Ir}(\text { ppy })_{2}(\right.$ bpy $\left.)\right] P F_{6}$ is elucidated in previous work, and the photoinitiated excited-state dynamics are described as follows: (1) the Franck-Condon excited-states form in $<30$ ps then decay to (2) a ${ }^{3} L L C T$ state formed within $2.6 \mathrm{~ns}$, (3) a ${ }^{3} M L C T_{p p y}$ formed in $<0.4 \mathrm{~ns}$, and (4) a ${ }^{3} M L C T_{b p y}$ formed within $4.8 \mathrm{~ns}$ (all time constants are from toluene measurements). ${ }^{58}$ This previous work describes emission from the ${ }^{3} L L C T,{ }^{3} M L C T_{p p y}$, and ${ }^{3} M L C T_{b p y}$ in $\tau_{e m}=617,643$, and $582 \mathrm{~ns}$, respectively in toluene, with the intensity of each band depending on the relative population of each state (see Fig. 7). 


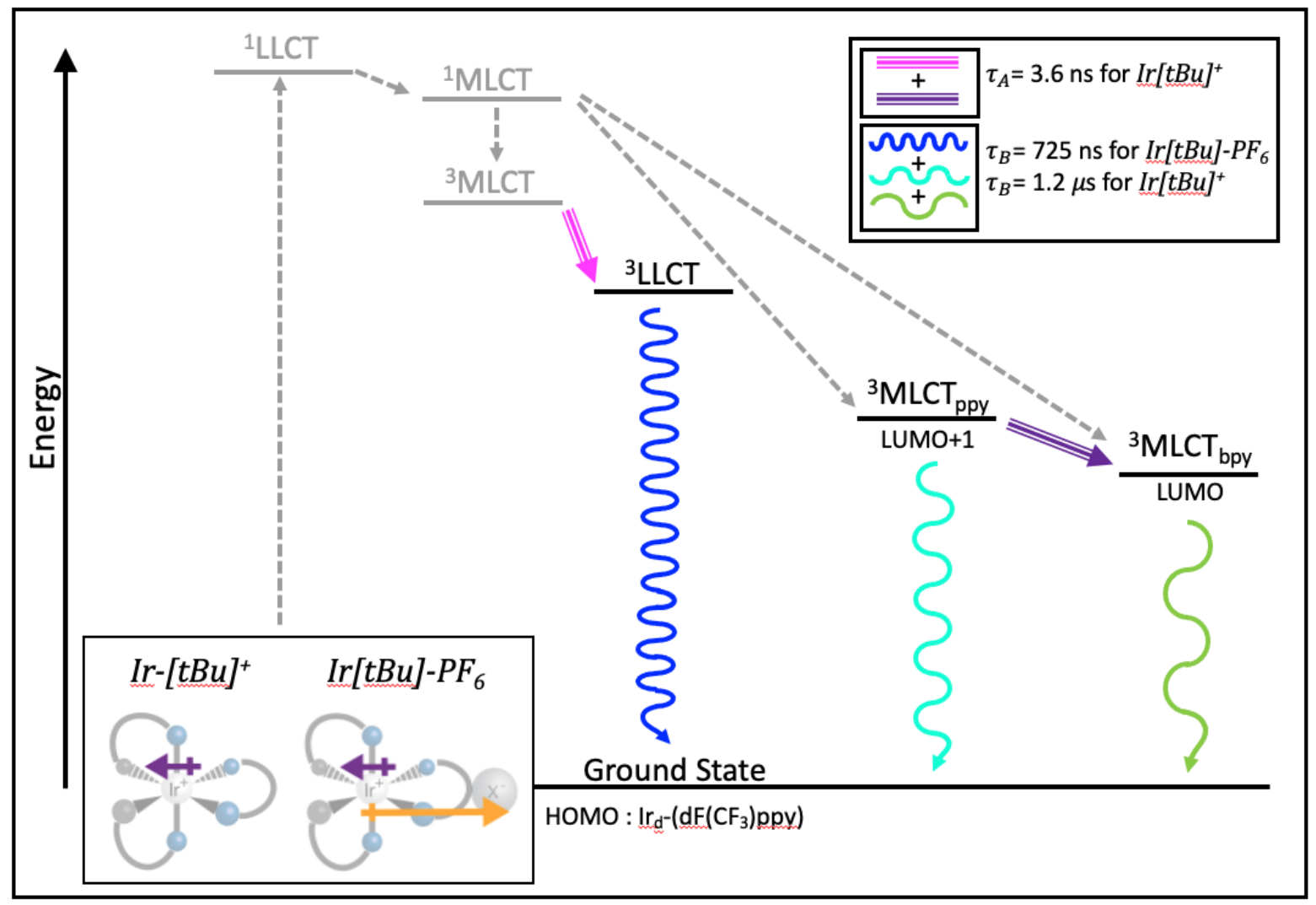

Figure 7. The proposed excited-state dynamics of $\operatorname{Ir}[t B u]-P F_{6}$ and $\operatorname{Ir}[t B u]-B A r_{4}^{F}$ (i.e. the unpaired $\operatorname{Ir}[t B u]^{+}$ion) in 1,4-dioxane based on the TRDL transients, and absorption and emission spectra $\left(\lambda_{e x}=415 \mathrm{~nm}\right)$. The transitions that occur within our system's IRF are included in grey and lead to Species A where the dipole moment of both Species is greater than its ground-state value. As Species A $\left({ }^{1} L L C T+{ }^{1} M L C T+{ }^{3} M L C T+{ }^{3} M L C T_{p p y}\right)$ decays to the emissive states of Species B $\left({ }^{3} L L C T+{ }^{3} M L C T_{p p y}+{ }^{3} M L C T_{b p y}\right)$, the $P F_{6}^{-}$counterion moves to cancel the intramolecular dipole. This rearrangement results in a dipole moment in Species B that is smaller than that of the ground-state for $\operatorname{Ir}[t B u]-P F_{6}$ and stabilization of the emitting state energies. In contrast, the Species B dipole in $\operatorname{Ir}[t B u]-B A r_{4}^{F}$ is larger than its ground-state value, representing the dipole dynamics of unpaired $\operatorname{Ir}[\mathrm{tBu}]^{+}$.

Considering the instrument response function of our system and the differing dielectric constants of toluene vs 1,4-dioxane, the literature mechanism described above agrees well with the measured time constant associated Species A's decay $\left(2.78 \cdot 10^{8}\right.$ $s^{-1}$, i.e. $\tau_{A}=3.60 \mathrm{~ns}$ ), which likely represents a rough average of the time constants associated with processes (2) and (4) above $\left(\tau_{a v g}=3.70 \mathrm{~ns}\right)$. The literature $\tau_{e m}$ values also agree well with our time-integrated decay constant of Species B in $\operatorname{Ir}[t B u]-P F_{6}, \tau_{B}=725 \mathrm{~ns}$ (see table 4 ), considering their work was performed on $\left[\operatorname{Ir}(p p y)_{2}(\right.$ bpy $\left.)\right] P F_{6}$ and the reported time constants varied with solvent dielectric environment. Notably, Wu et al., estimates the excited-state dipole to be $\sim 6.4 \mathrm{D}$ based on solvent induced shifting of the high energy emission band $\left(470 \mathrm{~nm}\right.$ in toluene, $\left.23^{\circ} \mathrm{C}\right)$ using the Mataga-Lippert equation. As this emission band is attributed to the ${ }^{3} L L C T$ and does not account for ion-pairing, this is in excellent agreement with our calculation for Species A of $\operatorname{Ir}[t B u]-B A r_{4}^{F}$.

Immediately after excitation, $\Delta \varepsilon^{\prime \prime}$ is similar in both complexes during the evolution of Species A. The dipole moment of Species A increases in both complexes relative to their respective ground-states, and this accompanies the formation of the Frank-Condon excited-states discussed above (large polarizability volume) seen in the $\Delta \varepsilon^{\prime}$ transient. However, as the system evolves to Species $\mathrm{B}, \operatorname{Ir}[t \mathrm{Bu}]-P F_{6}$ exhibits a negative change in the dipole moment (relative to the ground-state) whereas $\operatorname{Ir}[t B u]-B A r_{4}^{F}$ continues to exhibit a continued positive change.

In both $\operatorname{Ir}[t B u]-P F_{6}$ and $\operatorname{Ir}[t B u]-B A r_{4}^{F}$, Species B's kinetics align with those reported for its emissive states (and our measured photoluminescence for $\operatorname{Ir}[t B u]-P F_{6}$, see Supplementary Fig. S8 and S9), and $\Delta \varepsilon^{\prime}$ and $\Delta \varepsilon^{\prime \prime}$ evolve together. As mentioned in the literature on $\left[\operatorname{Ir}(p p y)_{2}(\text { bpy })\right]^{+}$, the emissive states have such similar lifetimes that they are difficult to differentiate. ${ }^{58,60,61}$ The negative $\Delta \varepsilon^{\prime \prime}$ from $\operatorname{Ir}[t \mathrm{Bu}]-P F_{6}$ indicates that the observed excited-state dipole moment associated with the relaxed MLCT state is less than that of its ground-state. This striking observation is consistent with a sub-nanosecond excited-state reorganization 
mechanism where the ion pair reorients to cancel the intramolecular dipole moment of the MLCT state, as inferred for the ground-state in the preceding section. Indeed, contact-ion pairing combined with this sort of excited-state reorganization will always result in an overall negative change in the dipole moment. Simply by virtue of the fact that the counter-ion must remain further from the molecular center than the ligand shell, it is impossible for the intramolecular dipole moment to exceed that associated with the intermolecular dipole moment. The fact that we do not see this negative change in the B Species of the $\operatorname{Ir}[t B u]-B A r_{4}^{F}$ complex is confirmation that the negative transient dipole moment is most likely due to ion-pair reorganization. As described previously on similar complexes, ion-pairing imposes an electrostatic restriction on the spatial geometry of the complex. ${ }^{35,36}$ This description agrees well with the differences we observe in the ground-state dipole moments and absorption spectra of $\operatorname{Ir}[t B u]-B A r_{4}^{F}$ vs $\operatorname{Ir}[t B u]-P F_{6}$ (See SI, Absorbance and emission spectroscopy). However, the ion-pair rearrangement in the excited-state alters the geometry of the coordination sphere to accommodate the charge redistribution. This rearrangement results in a slight stabilization of the emitting states. This stabilizing effect is evidenced by small bathochromic shifts in the emission bands, differences in the population of the ${ }^{3} M L C T_{d F}\left(C F_{3}\right) p p y / d t b p y$ (See Supplementary Fig. S8 and Supplementary Table S7), and a reduction of the excited-state lifetime. The observed shifts in emission profile and reduction in the lifetime for $\operatorname{Ir}[t B u]-P F_{6}$ vs $\operatorname{Ir}[t B u]-B A r_{4}^{F}$ also agree well with previous literature results. ${ }^{19,32,33,35,36}$

In both complexes, $\Delta \varepsilon^{\prime}$ shows a much larger charge delocalization for Species A over Species B, as inferred from the large polarizability volume. ${ }^{62}$ This makes sense in light of the highly mixed nature of the Frank-Condon and high-lying excited-states that result in LLCT. This could be important to understanding and improving the efficiency of a photoredox catalyst since the charges in Species A are more dispersed than in Species B. Extending the lifetime of Species A or chemically pre-associating the photoredox catalyst with target substrate could enhance the likelihood of charge transfer due to Species A having a larger dispersion of charge and thus improve the overall reaction.

Data from the $\operatorname{Ir}[t B u]-B A r_{4}^{F}$ complex provides the magnitude of the intramolecular dipole moment, which we use to compute absolute dipoles for each excited-state Species in table 4. We find that the dipole moment we observe for $I r[t B u]-B A r_{4}^{F}$ does not meet with our simplistic center-of-mass approximation, which suggests an MLCT-state dipole moment of 16.8 D. Instead, we observe a transient dipole moment of only $5.2 \pm 1.6 \mathrm{D}$ in the fully relaxed MLCT (Species B). This discrepancy could partly be accounted for if the ground and excited-state dipole moments oppose each other. However, even exact opposition would not make up the whole difference. We can eliminate the possibility that the small observed transient dipole moment is a more subtle manifestation of ion-pair reorganization by $B A r_{4}^{F}$, as the neutral homoleptic complex $\operatorname{Ir}(p p y)_{3}$ (see SI section Non-ionic Iridium(III) Complex) displays an even smaller change in excited-state dipole moment (see Supplementary Table S6). Rather, we posit that the excited-state dipole moment is intrinsically small in these complexes, consistent with the high degree of mixing between the orbitals involved. This indicates that the simplistic picture of the lowest MLCT state as an integer charge localized on the bpy ligand is incorrect for this complex, and is likely similar in other related Ir(III) photoredox catalysts.

Knowing the intramolecular dipole moment and the observed dipole moment of the $\operatorname{Ir}[t B u]-P F_{6}$ complex, the approximate distance between the iridium cation and phosphorous anion can be calculated using equation (14) for the ground-state and each excited-state Species. Table 5 summarizes this change in distance for $\operatorname{Ir}[t B u]-P F_{6}$.

Table 5. Approximate distances between the iridium cation and phosphorus anion for each state.

\begin{tabular}{|l|c|c|c|}
\hline & Ground-state & Species A & Species B \\
\hline Distance $(\AA)$ & $4.2 \pm 2$ & $4.3 \pm 2$ & $3.9 \pm 2$ \\
\hline
\end{tabular}

Distance calculations show that the $\mathrm{PF}_{6}^{-}$counter anion is not effected by Species A, this could be because the ground-state dipole of the $\operatorname{Ir}[t B u]^{+}$is pointing in the same direction as the Species A dipole, or because Species A decays faster than the reorganizational response time of the $P F_{6}^{-}$counter anion. In Species B, the distance between the ions decrease by $0.4 \AA$ which can be explained by the intramolecular dipole moment of $\operatorname{Ir}[t B u]^{+}$reorganizing to point away from the $d F\left(C F_{3}\right) p p y$ ligands as the excited electron settles closer to the dtbpy ligand. This change in dipole direction causes the $P F_{6}^{-}$counter anion to move between the two $d F\left(C F_{3}\right)$ ppy ligands of the $\operatorname{Ir}[t B u]^{+}$complex which, due to the smaller size of the $d F\left(C F_{3}\right) p p y$ ligands compared to the $d t b p y$ ligand, allows the $\mathrm{PF}_{6}^{-}$to get closer to the positively-charged iridium center.

\section{Conclusion}

In this work we have applied modern computational methods to revitalize time-resolved dielectric-loss spectroscopy as a foundational tool for studying the ground and excited-state electronic configuration of molecules in solution. Electromagnetic simulations of the microwave cavity response function and calculation of molecular dipolar relaxation time improve on the accuracy and broad applicability of the technique. We verify our methods by showing agreement with past literature on the model compound N,N-dimethylaminobenzonitrile. Application of TRDL to $\left(\left[\operatorname{Ir}\left[d F\left(C F_{3}\right) p p y\right]_{2}(d t b p y)\right] X\right)$, a photocatalyst of great interest in the modern renaissance of light escalated chemistry, reveals dramatic changes in the dipole moment in both 
ground and excited-states depending on the identity of the counter ion $X^{-}$. Contact-ion pairing is observed in 1,4-dioxane when $X=P F_{6}^{-}$, and there is a negative change in the dipole moment upon photoexcitation. In contrast, when $X=B A r_{4}^{F}$ we observe no evidence of contact ion pairs, and the change in dipole moment upon photoexcitation is positive, as expected. These results are consistent with an excited-state ion-pair reorganization mechanism that cancels the dipole moment of the lowest-lying MLCT state when $X=P F_{6}^{-}$. We suggest that this phenomenon may explain the recently observed dependence of photocatalytic activity on counter-ion identity in similar iridium(III)-based photocatalysts. ${ }^{25}$ Ion pair reorganisation can be expected to reduce the excited-state potential energy and the proposed migration of the counter anion to the most positively charged region of the complex may limit the ability of these catalysts to drive oxidative chemistry. Finally, unrelated to ion pair dynamics, the measured dipole moment of the relaxed $M L C T_{d t b p y}$ state in $\left[\operatorname{Ir}\left[d F\left(C F_{3}\right) p p y\right]_{2}(d t b p y)\right] X$ is much smaller than naive point-charge calculations suggest, which, combined with a small polarizability volume indicate a rather localized final state of mixed metal-ligand character, in contrast with the highly polarizable initial MLCT states observed on the timescale of our instrument response. Future work should explicitly test to what extent ion pair reorganisation, the excited-state dipole moment and polarizability volume of photoredox catalysts may influences their reactivity.

\section{References}

1. Wagenknecht, P. S. \& Ford, P. C. Metal centered ligand field excited states: Their roles in the design and performance of transition metal based photochemical molecular devices. Coord. Chem. Rev. 255, 591-616, DOI: 10.1016/j.ccr.2010.11.016 (2011).

2. Sakai, H. A., Liu, W., Le, C. \& MacMillan, D. W. Cross-Electrophile Coupling of Unactivated Alkyl Chlorides. J. Am. Chem. Soc. 142, 11691-11697, DOI: 10.1021/jacs.0c04812 (2020).

3. Chen, T. Q. \& MacMillan, D. W. A Metallaphotoredox Strategy for the Cross-Electrophile Coupling of $\alpha$-Chloro Carbonyls with Aryl Halides. Angewandte Chemie - Int. Ed. 58, 14584-14588, DOI: 10.1002/anie.201909072 (2019).

4. Nguyen, S. T., Murray, P. R. \& Knowles, R. R. Light-driven depolymerization of native lignin enabled by proton-coupled electron transfer. ACS Catal. 10, 800-805, DOI: 10.1021/acscatal.9b04813 (2020).

5. Zhang, J. Conversion of Lignin Models by Photoredox Catalysis. ChemSusChem 11, 3071-3080, DOI: 10.1002/cssc. 201801370 (2018).

6. Daub, M. E. et al. Enantioselective [2+2] Cycloadditions of Cinnamate Esters: Generalizing Lewis Acid Catalysis of Triplet Energy Transfer. J. Am. Chem. Soc. 141, 9543-9547, DOI: 10.1021/jacs.9b04643 (2019).

7. Zhou, Y., Xiong, Z., Qiu, J., Kong, L. \& Zhu, G. Visible light photocatalytic acyldifluoroalkylation of unactivated alkenes for the direct synthesis of: Gem -difluorinated ketones. Org. Chem. Front. 6, 1022-1026, DOI: 10.1039/c9qo00136k (2019).

8. Arias-Rotondo, D. M. \& McCusker, J. K. The photophysics of photoredox catalysis: A roadmap for catalyst design. Chem. Soc. Rev. 45, 5803-5820, DOI: 10.1039/c6cs00526h (2016).

9. Porras, J. A., Mills, I. N., Transue, W. J. \& Bernhard, S. Highly Fluorinated Ir(III)-2,2':6',2”-Terpyridine-Phenylpyridine-X Complexes via Selective C-F Activation: Robust Photocatalysts for Solar Fuel Generation and Photoredox Catalysis. $J$. Am. Chem. Soc. 138, 9460-9472, DOI: 10.1021/jacs.6b03246 (2016).

10. You, N., Kim, K. S., Ahn, T. K., Kim, D. \& Park, S. Y. Direct spectroscopic observation of interligand energy transfer in cyclometalated heteroleptic iridium(III) complexes: A strategy for phosphorescence color tuning and white light generation. J. Phys. Chem. C 111, 4052-4060, DOI: 10.1021/jp0702550 (2007).

11. Lowry, M. S. et al. Single-layer electroluminescent devices and photoinduced hydrogen production from an ionic iridium(III) complex. Chem. Mater. 17, 5712-5719, DOI: 10.1021/cm051312+ (2005).

12. De Angelis, F. et al. Controlling phosphorescence color and quantum yields in cationic iridium complexes: A combined experimental and theoretical study. Inorg. Chem. 46, 5989-6001, DOI: 10.1021/ic700435c (2007).

13. Radwan, Y. K., Maity, A. \& Teets, T. S. Manipulating the Excited States of Cyclometalated Iridium Complexes with $\beta$-Ketoiminate and $\beta$-Diketiminate Ligands. Inorg. Chem. 54, 7122-7131, DOI: 10.1021/acs.inorgchem.5b01401 (2015).

14. Spaenig, F. et al. Excited-state properties of heteroleptic iridium(III) complexes bearing aromatic hydrocarbons with extended cores. Inorg. Chem. 50, 10859-10871, DOI: 10.1021/ic201397v (2011).

15. Lowry, M. S. \& Bernhard, S. Synthetically tailored excited states: Phosphorescent, cyclometalated iridium(III) complexes and their applications. Chem. - A Eur. J. 12, 7970-7977, DOI: 10.1002/chem.200600618 (2006). 
16. Slinker, J. D. et al. Efficient Yellow Electroluminescence from a Single Layer of a Cyclometalated Iridium Complex. $J$. Am. Chem. Soc. 126, 2763-2767, DOI: 10.1021/ja0345221 (2004).

17. Lowry, M. S., Hudson, W. R., Pascal, R. A. \& Bernhard, S. Accelerated luminophore discovery through combinatorial synthesis. J. Am. Chem. Soc. 126, 14129-14135, DOI: 10.1021/ja047156+ (2004).

18. Diluzio, S. et al. High-Throughput Screening and Automated Data-Driven Analysis of the Triplet Photophysical Properties of Structurally Diverse, Heteroleptic Iridium(III) Complexes. J. Am. Chem. Soc. 143, 1179-1194, DOI: 10.1021/jacs. 0c12290 (2021).

19. Tschierlei, S. et al. Ultrafast excited state dynamics of iridium(iii) complexes and their changes upon immobilisation onto titanium dioxide layers. Phys. Chem. Chem. Phys. 18, 10682-10687, DOI: 10.1039/c6cp00343e (2016).

20. Li, J. et al. Synthetic Control of Excited-State Properties in Cyclometalated Ir(III) Complexes Using Ancillary Ligands. Inorg. Chem. 44, 1713-1727, DOI: 10.1021/ic048599h (2005).

21. Balzani, V., Sabbatini, N. \& Scandola, F. "Second-Sphere" Photochemistry and Photophysics of Coordination Compounds. Chem. Rev. 86, 319-337, DOI: 10.1021/cr00072a002 (1986).

22. Marcus, Y. \& Hefter, G. Ion pairing. Chem. Rev. 106, 4585-4621, DOI: 10.1021/cr040087x (2006).

23. Macchioni, A. Ion pairing in transition-metal organometallic chemistry. Chem. Rev. 105, 2039-2073, DOI: 10.1021/ cr0300439 (2005).

24. Tsuboi, T. Optical and Thermal Electron Transfer in KCl: Tl+ Crystals. Zeitschrift fur Naturforschung - Sect. A J. Phys. Sci. 33, 1154-1157, DOI: 10.1515/zna-1978-1005 (1978).

25. Farney, E. P. et al. Discovery and Elucidation of Counteranion Dependence in Photoredox Catalysis. J. Am. Chem. Soc. 141, 6385-6391, DOI: 10.1021/jacs.9b01885 (2019).

26. Strauss, S. H. The Search for Larger and More Weakly Coordinating Anions. Chem. Rev. 93, 927-942, DOI: 10.1021/ cr00019a005 (1993).

27. Appelhans, L. N. et al. An anion-dependent switch in selectivity results from a change of C-H activation mechanism in the reaction of an imidazolium salt with IrH 5(PPh3)2. J. Am. Chem. Soc. 127, 16299-16311, DOI: 10.1021/ja055317j (2005).

28. Song, L. \& Trogler, W. C. Mechanism of Halide-Induced Disproportionation of M(CO)3(PCy3)2+ 17-Electron Radicals ( $\mathrm{M}=\mathrm{Fe}, \mathrm{Ru}, \mathrm{Os}$ ). Periodic Trends on Reactivity and the Role of Ion Pairs Lin. Tech. Rep. (1992).

29. Troian-Gautier, L., Beauvilliers, E. E., Swords, W. B. \& Meyer, G. J. Redox Active Ion-Paired Excited States Undergo Dynamic Electron Transfer. J. Am. Chem. Soc 138, 16815-16826, DOI: 10.1021/jacs.6b11337 (2016).

30. Uraguchi, D., Kimura, Y., Ueoka, F. \& Ooi, T. Urea as a Redox-Active Directing Group under Asymmetric Photocatalysis of Iridium-Chiral Borate Ion Pairs. J. Am. Chem. Soc. 142, 19462-19467, DOI: 10.1021/jacs.0c09468 (2020).

31. Tellers, D. M., Yung, C. M., Arndtsen, B. A., Adamson, D. R. \& Bergman, R. G. Electronic and medium effects on the rate of arene C-H bond activation by cationic Ir(III) complexes. J. Am. Chem. Soc. 124, 1400-1410, DOI: 10.1021/ja011809u (2002).

32. Morton, C. M. et al. C-H Alkylation via Multisite-Proton-Coupled Electron Transfer of an Aliphatic C-H Bond. DOI: 10.1021/jacs.9b06834 (2019).

33. Ruccolo, S., Qin, Y., Schnedermann, C. \& Nocera, D. G. General Strategy for Improving the Quantum Efficiency of Photoredox Hydroamidation Catalysis. J. Am. Chem. Soc. 140, 14926-14937, DOI: 10.1021/jacs.8b09109 (2018).

34. Marton, A. et al. Static and dynamic quenching of Ru(II) polypyridyl excited states by iodide. Inorg. Chem. 45, 362-369, DOI: 10.1021/ic051467j (2006).

35. Vining, W. J., Caspar, J. V. \& Meyer, T. J. The influence of environmental effects on excited-state lifetimes. The effect of ion pairing on metal-to-ligand charge transfer excited states. J. Phys. Chem. 89, 1095-1099, DOI: 10.1021/j100253a010 (1985).

36. Ward, W. M., Farnum, B. H., Siegler, M. \& Meyer, G. J. Chloride ion-pairing with Ru(II) polypyridyl compounds in dichloromethane. J. Phys. Chem. A 117, 8883-8894, DOI: 10.1021/jp404838z (2013).

37. Prier, C. K., Rankic, D. A. \& MacMillan, D. W. C. Visible Light Photoredox Catalysis with Transition Metal Complexes: Applications in Organic Synthesis. Chem. Rev. 113, 5322-5363, DOI: 10.1021/cr300503r (2013).

38. Smith, R. T. et al. Metallaphotoredox-Catalyzed Cross-Electrophile C sp3 -C sp3 Coupling of Aliphatic Bromides. J. Am. Chem. Soc. 140, 17433-17438, DOI: 10.1021/jacs.8b12025 (2018). 
39. Britz, A. et al. Site-Selective Real-Time Observation of Bimolecular Electron Transfer in a Photocatalytic System Using L-Edge X-Ray Absorption Spectroscopy**. ChemPhysChem 22, 693-700, DOI: 10.1002/cphc.202000845 (2021).

40. Warman, J. M., Jonker, S. A., de Haas, M. P., Verhoeven, J. W. \& Paddon-Row, M. N. <title>Photon-induced charge separation in molecular systems studied by time-resolved microwave conductivity: molecular optoelectric switches $</$ title $>$. Photopolym. Device Physics, Chem. Appl. II 1559, 159-170, DOI: 10.1117/12.50666 (1991).

41. Fessenden, R. W. \& Hitachi, A. A study of the dielectric relaxation behavior of photoinduced transient species. J. Phys. Chem. 91, 3456-3462, DOI: 10.1021/j100296a070 (1987).

42. Hoogesteger, F. J. et al. Photoinduced intramolecular charge separation in donor/acceptor-substituted bicyclohexylidene and bicyclohexyl. Chem. - A Eur. J. 6, 2948-2959, DOI: 10.1002/1521-3765(20000818)6:16<2948::AID-CHEM2948>3. $0 . \mathrm{CO} ; 2-0(2000)$.

43. Onimisi. M.Y, I. J. Comparative Analysis of Dielectric Constant and Loss Factor of Pure Butan-1-ol and Ethanol. Am. J. Condens. Matter Phys. 5, 69-75, DOI: 10.5923/j.ajcmp.20150503.02 (2015).

44. Fessenden, R. W., Carton, P. M., Shimamori, H. \& Scalano, J. C. Measurement of the dipole moments of excited states and photochemical transients by microwave dielectric absorption. J. Phys. Chem. 86, 3803-3811, DOI: 10.1021/j100216a020 (1982).

45. Reid, O. G. et al. Quantitative analysis of time-resolved microwave conductivity data. J. Phys. D: Appl. Phys. 50, DOI: 10.1088/1361-6463/aa9559 (2017).

46. De Haas, M. P. \& Warman, J. M. Photon-induced molecular charge separation studied by nanosecond time-resolved microwave conductivity. Chem. Phys. 73, 35-53, DOI: 10.1016/0301-0104(82)85148-3 (1982). 0301-0104(82)85148-3.

47. Schuddeboom, W., Warman, J. M., Van der Auweraer, M., de Schryver, F. C. \& Declercq, D. D. Dipolar exciton states of molecules with threefold symmetry. Chem. Phys. Lett. 222, 586-591, DOI: 10.1016/0009-2614(94)00401-3 (1994).

48. Warman, J. M., De Haas, M. P., Hummel, A., Varma, C. A. \& Van Zeyl, P. H. Dipole moment changes in the singlet and triplet excited states of 4-dimethylamino-4'-nitrostilbene detected by nanosecond time-resolved microwave conductivity. Chem. Phys. Lett. 87, 83-86, DOI: 10.1016/0009-2614(82)83560-4 (1982).

49. Jonker, S. A. \& Warman, J. M. Highly dipolar excited states of a symmetrical bound dimer of dimethylaminobenzonitrile observed by TRMC. Chem. Phys. Lett. 185, 36-40, DOI: 10.1016/0009-2614(91)80135-K (1991).

50. Ma, C. et al. Excited states of 4-aminobenzonitrile (ABN) and 4-dimethylaminobenzonitrile (DMABN): Time-resolved resonance Raman, transient absorption, fluorescence, and ab initio calculations. J. Phys. Chem. A 106, 3294-3305, DOI: $10.1021 / \mathrm{jp} 012765 \mathrm{e}(2002)$.

51. Okada, T. et al. Time-resolved spectroscopy of DMABN and its cage derivatives 6-cyanobenzquinuclidine (CBQ) and benzquinuclidine (BQ). Chem. Phys. 241, 327-337, DOI: 10.1016/S0301-0104(98)00411-X (1999).

52. Schuddeboom, W. et al. Excited-state dipole moments of dual fluorescent 4-(dialkylamino)benzonitriles. Influence of alkyl chain length and effective solvent polarity. J. Phys. Chem. 96, 10809-10819, DOI: 10.1021/j100205a041 (1992).

53. Visser, R. J., Weisenborn, P. C. M. \& Varma, C. A. G. O. Dipole moments of singlet and triplet excited states of 4-N,Ndimethylaminobenonitrile and related compounds and of their solute-solvent exciplexes. 104, DOI: 10.1021/j100205a041 (1984).

54. Demeter, A. \& Zachariasse, K. A. Triplet state dipole moments of aminobenzonitriles. J. Phys. Chem. A 112, 1359-1362, DOI: $10.1021 /$ jp0747959 (2008).

55. You, Y. \& Nam, W. Photofunctional triplet excited states of cyclometalated $\operatorname{Ir}($ iii) complexes: Beyond electroluminescence. Chem. Soc. Rev. 41, 7061-7084, DOI: 10.1039/c2cs35171d (2012).

56. Wilde, A. P., King, K. A. \& Watts, R. J. Resolution and analysis of the components in dual emission of mixed-chelate/orthometalate complexes of iridium(III). J. Phys. Chem. 95, 629-634, DOI: 10.1021/j100155a026 (1991).

57. Scattergood, P. A. et al. Unravelling the Mechanism of Excited-State Interligand Energy Transfer and the Engineering of Dual Emission in $\left[\operatorname{Ir}\left(\mathrm{C}^{\wedge} \mathrm{N}\right) 2\left(\mathrm{~N}^{\wedge} \mathrm{N}\right)\right]+$ Complexes. 22, 29, DOI: 10.1021/acs.inorgchem.9b03003 (2021).

58. Wu, S. H. et al. Dynamics of the excited states of [ $\operatorname{Ir}(\mathrm{ppy}) 2 \mathrm{bpy}]+$ with triple phosphorescence. J. Phys. Chem. A 114, 10339-10344, DOI: 10.1021/jp102264q (2010).

59. Hay, P. J. Theoretical studies of the ground and excited electronic states in cyclometalated phenylpyridine $\operatorname{Ir}(\mathrm{III})$ complexes using density functional theory. J. Phys. Chem. A 106, 1634-1641, DOI: 10.1021/jp013949w (2002). 
60. King, K. A. \& Watts, R. J. Dual Emission from an Ortho-Metalated Ir(III) Complex. J. Am. Chem. Soc. 109, 1589-1590, DOI: $10.1021 / \mathrm{ja} 00239 \mathrm{a} 060$ (1987).

61. Wilde, A. P. \& Watts, R. J. Solvent effects on metal-to-Ligand charge-transfer bands in ortho-metalated complexes of iridium(III): Estimates of transition dipole moments. J. Phys. Chem. 95, 622-629, DOI: 10.1021/j100155a025 (1991).

62. Piet, J. J., Warman, J. M., Baumgarten, M. \& Müllen, K. Dipolar excitonic states of oligo-anthrylenes. J. Phys. Chem. A 106, 2318-2321, DOI: 10.1021/jp012870o (2002).

\section{Acknowledgements}

This work was supported by the US Department of Energy, Office of Science, as part of BioLEC EFRC under grant DE-SC0019370.

This work was authored, in part, by the National Renewable Energy Laboratory, operated by Alliance for Sustainable Energy, LLC, for the U.S. Department of Energy (DOE) under Contract No. DE-AC36-08GO28308.

This article is submitted in fond memory of the late Professor John Warman (TU Delft, NL 1939-2020), whose seminal research laid the foundation for transient microwave spectroscopy, and the dielectric loss spectroscopy that is described here.

\section{Author contributions statement}

G.R., O.G.R., J.D.E., A.Z., and J.K.M conceived the experiments; O.G.R., J.D.E., A.Z., and Z.J.M conducted the experiments; G.R., O.G.R., J.D.E., A.Z., M.S.L., and H.H.R. analyzed the results; H.H.R. performed synthesis. All authors reviewed and contributed to development of the manuscript. 